\title{
Bumps over cheeks
}

\section{Hatice Tuba Sanal $•$ Kemal Hasanov $\cdot$ Nebi Caferov $\cdot$ Lina Chen}

Published online: 26 June 2013

(C) ISS 2013

\section{Question}

Twenty one year old draftee under evaluation of medical qualification. A panoramic radiograph (Fig. 1) and CT scan of his skull (Fig. 2) was performed.

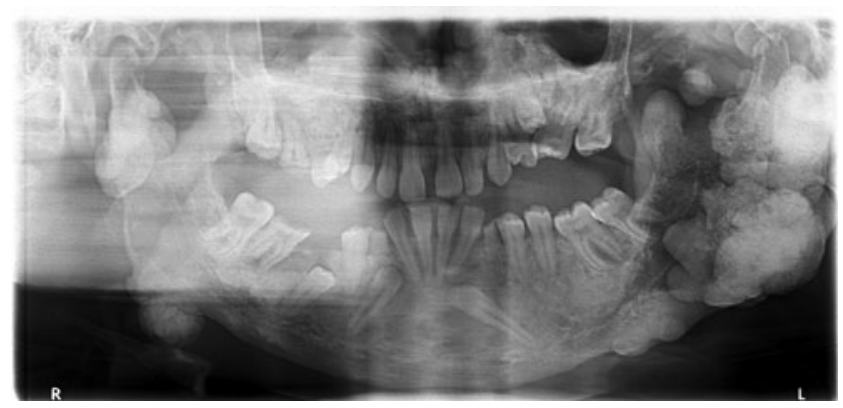

Fig. 1 Panoramic radiograph

The diagnosis can be found at doi: 10.1007/s00256-013-1679-3.

H. T. Sanal $(\bowtie) \cdot$ K. Hasanov $\cdot$ N. Caferov

Department of Radiology, Gulhane Military Medical Academy,

Medical Faculty, 06018 Kecioren, Ankara, Turkey

e-mail: tubasanal@gmail.com

\section{Chen}

University of Maryland School of Medicine, 22 South Greene

Street, Baltimore, MD 21201, USA

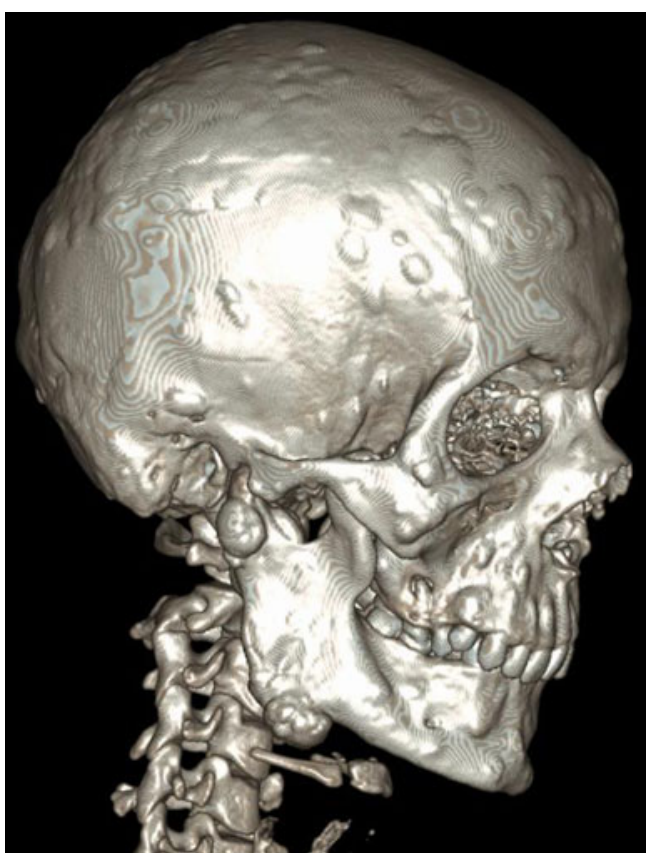

Fig. 2 3D surface shaded image of skull

Conflict of interest The authors declare that they have no conflict of interest. 